\title{
Desain Modifikasi Struktur Gedung Apartemen Gunawangsa Tidar Surabaya Menggunakan Struktur Beton Bertulang dengan Sistem Outrigger dan Belt-Truss
}

\author{
Faimun, Tavio dan Fauzan Kurnianto \\ Departemen Teknik Sipil, Teknik Sipil dan Perencanaan, Institut Teknologi Sepuluh Nopember (ITS)
} e-mail: tavio@ce.its.ac.id

\begin{abstract}
Abstrak-Gunawangsa Tidar Surabaya memiliki 3 buah tower dengan 37 lantai pada setiap towernya. Dengan ketinggian hingga \pm 115 meter dan struktur bangunan yang langsing, simpangan yang terjadi akibat beban lateral cenderung berlebihan. Untuk mengatasi masalah tersebut, bangunan perlu dimodifikasi agar performa bangunan dalam menahan beban lateral lebih baik lagi. Namun jika sistem struktur yang biasa dipertahankan, dimensi elemen struktur yang dibutuhkan akan menjadi lebih besar dan mengurangi ruang. Maka diperlukan alternatif solusi untuk mengurangi simpangan yang terjadi tanpa memperbesar dimensi elemen struktur yang sudah ada. Dengan mempertahankan dimensi elemen struktur beton yang sudah ada, bangunan dimodifikasi menggunakan sistem outrigger dan belt-truss. Sistem outrigger dan belt-truss efektif dalam meningkatkan kekakuan bangunan. Balok outrigger dipasang menghubungkan corewall dan kolom eksterior. Sedangan belttruss dipasang menghubungkan antar kolom eksterior. Sehingga masalah simpangan yang berlebihan akibat beban lateral dapat teratasi. Dari hasil perencanaan diketahui simpangan lantai terbesar terletak pada hampir setengah dari total ketinggian bangunan. Maka balok outrigger dan belt-truss dipasang di ketinggian tersebut, tepatnya pada lantai 22. Dimensi balok outrigger dan belt truss adalah 400 x $2000 \mathrm{~mm}$. Dan dari analisa menggunakan program bantu Extract didapat nilai daktilitas kolom outrigger sebesar 6,76. Dengan demikian nilai koefisien reduksi untuk gempa $(R=5)$ yang digunakan sebagai perencanaan beban gempa sudah memenuhi.
\end{abstract}

Kata Kunci-Belt-truss, Extract, Gempa, Outrigger, Struktur Beton.

\section{PENDAHULUAN}

G unawangsa Tidar adalah apartemen yang mengusung konsep Mix Use High-Rise Building. Apartemen yang terletak di Jalan Tidar no. 350 Surabaya ini menyediakan unit - unit Hunian, Hotel bintang 4, Komersial, Bisnis, dan fasilitas yang lengkap. Bangunan ini memiliki 3 buah tower dengan 37 lantai pada setiap towernya. Dengan ketinggian hingga \pm 115 meter, bangunan dapat digolongkan sebagai bangunan bertingkat tinggi. Pada bangunan bertingkat tinggi, beban lateral menjadi lebih dominan. Karena struktur bangunan yang tinggi dan langsing, maka simpangan yang terjadi akibat beban lateral cenderung berlebihan. Shingga dapat mengurangi kenyamanan penghuni didalamnya.

Untuk mengatasi masalah tersebut perlu dilakukan modifikasi struktur bangunan. Dengan mempertahankan struktur beton bertulang dan dimensi yang sudah ada, bangunan dimodifikasi menggunakan sistem outrigger dan belt-truss. Sistem outrigger bekerja ketika dikenai beban lateral, kolom eksterior yang terhubung balok outrigger menahan rotasi pada corewall, menyebabkan simpangan lateral dan momen pada corewall menjadi lebih kecil [1]. Sedangkan peran dari belt-truss adalah sebagai pengaku, dimana sistem outrigger yang menggunakan belt-truss memiliki simpangan lebih kecil daripada sistem outrigger tanpa belt-truss [1]. Sehingga simpangan bangunan dapat diminimalkan atau bahkan dihilangkan. Hal ini sesuai dengan Ali dan Moon [2] yang menyatakan bahwa masalah kemampuan layan seperti simpangan lateral, getaran lantai, dan kenyamanan pengunjung pada gedung bertingkat tinggi perlu diberi perhatian lebih.

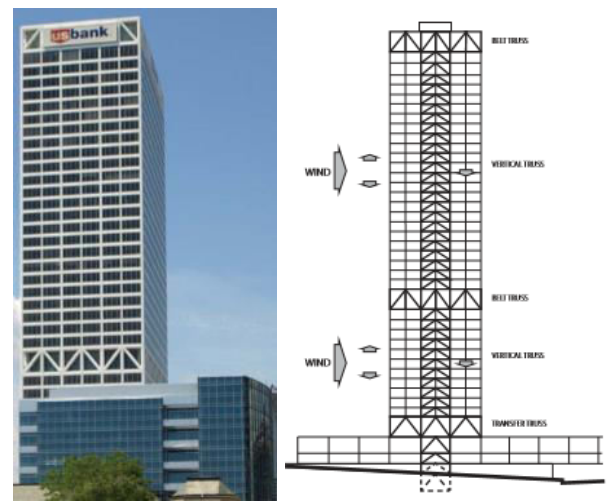

Gambar 1. U.S. Bank Center, Wisconsin [3].

Contoh bangunan yang menggunakan sistem outrigger dan belt-truss adalah U.S. Bank Center dapat dilihat pada Gambar 1. Dibandingkan dengan sistem penahan momen seperti Sistem Rangka Pemikul Momen (SRPM) dan sistem penahan momen berpengaku yang juga berfungsi sebagai penahan beban lateral atau yang biasa disebut Sistem Rangka Bresing (SRB), sistem outrigger dan belt-truss memiliki performa yang lebih baik meskipun dimensi struktur yang digunakan lebih kecil [4]. Dengan jumlah lantai yang sama, biaya pelaksanaan bangunan yang menggunakan outrigger relatif lebih murah dibandingkan bangunan tanpa outrigger meskipun waktu pelaksanaannya sedikit lebih lama [5].

Artikel ini akan membahas desain modifikasi struktur gedung apartemen gunawangsa tidar surabaya menggunakan struktur beton bertulang dengan sistem outrigger dan belttruss. Bangunan akan dimodifikasi yang semula simpangan bangunan tidak memenuhi syarat SNI [6] kemudian dipasang balok outrigger hingga simpangan bangunan memenuhi syarat SNI [6]. Selain itu juga dilakukan perhitungan nilai daktilitas struktur dengan pendeketan tertentu. Dimana akan ada kaitannya dengan koefisien reduksi (R) untuk mendesain beban gempa yang mana untuk sistem outrigger dan belt-truss ini tidak disebutkan secara spesifik di SNI [6]. Sehingga didapat hasil desain yang baik dan benar sesuai dengan syarat SNI [6][7][8] dan peraturan - peraturan lain yang terkait [9][10][11].

\section{LANDASAN TEORI}

\section{A. Sistem Outrigger dan Belt-truss}

Keindahan dan efisiensi dari sistem outrigger telah tercatat dengan baik dalam sejarah. Sistem ini juga menjadi salah satu kunci dalam mendesain sistem yang efisien dan ekonomis dalam bangunan bertingkat tinggi [12]. Sistem outrigger bekerja ketika dikenai beban lateral, kolom luar yang terhubung balok outrigger menahan rotasi pada kolom inti, menyebabkan simpangan lateral dan momen pada kolom inti 
menjadi lebih kecil [1]. Sedangkan belt-truss berfungsi sebagai pengaku horisontal yang mengikat kolom luar untuk ambil bagian dalam menahan rotasi yang terjadi pada kolom inti. Penggunaan belt-truss dapat meningkatkan kekakuan bangunan hingga sebesar 25\% - 35\% [12]. Sehingga sistem outrigger dan belt-truss biasanya digunakan sebagai salah satu sistem struktural untuk mengontrol simpangan yang berlebihan akibat beban lateral, baik akibat beban gempa maupun beban angin. Untuk bangunan bertingkat tinggi yang terletak di zona gempa aktif atau beban angin dominan, sistem ini dapat dipilih sebagai sistem struktur yang tepat [13].

Sistem outrigger dan belt-truss akan bekerja secara efektif bergantung letak dari outrigger tersebut dipasang. Selain tata letak, jumlah dari outrigger yang dipasang juga berpengaruh pada kemampuan bangunan dalam menahan beban lateral. Gambar 2 adalah contoh dari bentuk defleksi dan momen yang terjadi pada struktur yang menggunakan sistem outrigger. Bentuk defleksi dan momen yang terjadi bervariasi sesuai dengan tata letak dari balok outrigger.

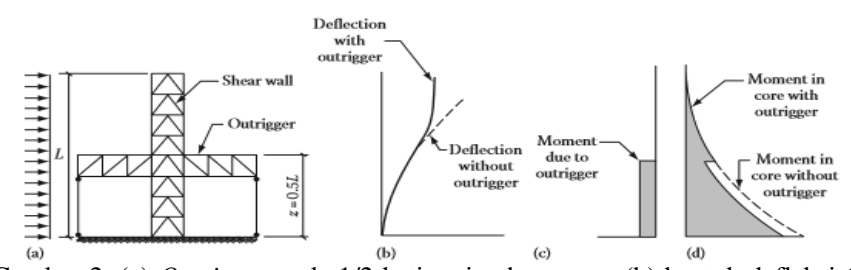

Gambar 2. (a) Outrigger pada $1 / 2^{\text {(b) }}$ ketinggian bangunan (b) bentuk defleksi (c dan d) diagram momen [11].

\section{B. Daktilitas Struktur dan Faktor Reduksi (R)}

Untuk struktur dengan sistem outrigger dan belt-truss nilai koefisien reduksi gempa (R) tidak dijelaskan secara spesifik pada SNI [6]. Dimana nilai R ada kaitannya dengan daktilitas suatu struktur bangunan. Semakin besar nilai $\mathrm{R}$ maka gaya gempa semakin kecil namun daktilitas yang disediakan struktur semakin besar, begitu pula sebaliknya. Untuk perencenaan ini akan digunakan $\mathrm{R}=5$ dengan detailing rangka menggunakan SRPMM. Setelah didapat hasil akhir berupa dimensi elemen struktur dan detailing penulangan, akan dicek nilai daktilitas elemen struktur menggunakan program bantu Extract. Elemen struktur yang akan dianalisis daktilitasnya adalah kolom eksterior, karena dianggap yang paling kritis.

\section{ANALISIS DAN PEMBAHASAN}

\section{A. Bangunan yang ditinjau}

Pada perencanaan ini bangunan yang ditinjau adalah Apartemen Gunawangsa Tidar Surabaya. Bangunan dimodifikasi menjadi 50 lantai dengan ketinggian $\pm 178,5 \mathrm{~m}$ seperti pada Gambar 2 dan denah dapat dilihat pada Gambar 3.
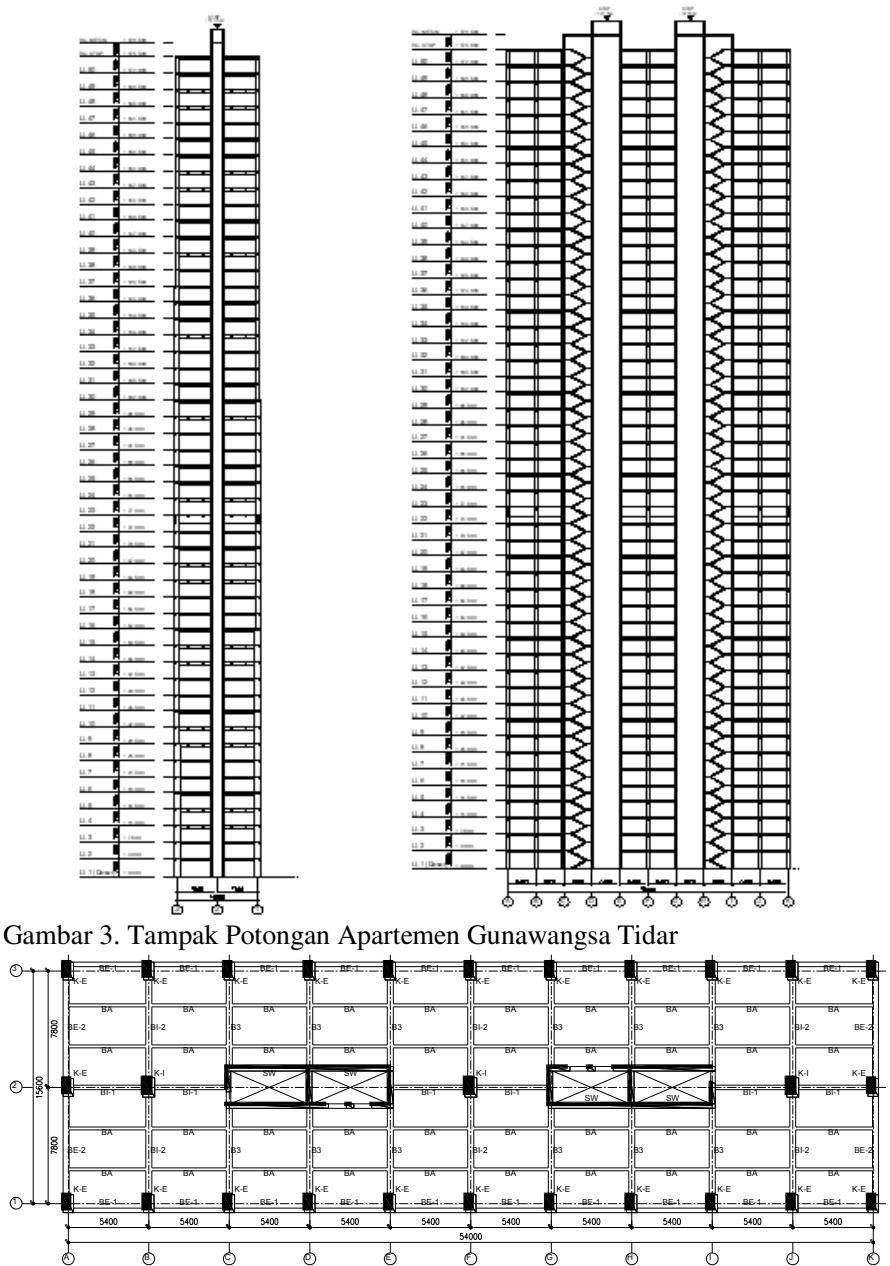

Gambar 4. Denah Apartemen Gunawangsa Tidar.

Dari Gambar 3 dan Gambar 4 digunakan dimensi elemen struktur:

1. Balok

Baik balok anak maupun balok induk menggunakan mutu beton $\mathrm{f}^{\prime} \mathrm{c}=30 \mathrm{Mpa}$ dengan dimensi seperti yang disajikan pada Tabel 1 .

Tabel 1.

Rekapitulasi dimensi balok

\begin{tabular}{llll} 
& \multicolumn{3}{c}{ Rekapitulasi dimensi balok } \\
\hline \hline Tipe & Bentang $(\mathrm{m})$ & Lebar $(\mathrm{cm})$ & Tinggi $(\mathrm{cm})$ \\
\hline BI-1 & 5,4 & 30 & 40 \\
BI-2 & 7,8 & 40 & 60 \\
BA & 5,4 & 20 & 35 \\
BL & 5,4 & 30 & 40 \\
\hline \hline
\end{tabular}

2. Pelat

Pelat menggunakan mutu yang sama dengan balok, yaitu f'c $=30 \mathrm{Mpa}$. Hal ini bertujuan untuk memudahkan ketika proses pelaksanaan.

$\begin{array}{ll}\text { - Pelat lantai dan atap } & (\mathrm{t})=120 \mathrm{~mm} \\ \text { - Pelat tangga } & (\mathrm{t})=150 \mathrm{~mm}\end{array}$

\section{Kolom}

Pada Apartemen Gunawangsa Tidar ini dimensi kolom dibedakan setiap 7 lantai. Sehingga dimensi kolom dapat dikelompokan seperti pada Tabel 2.

Tabel 2.

Rekapitulasi dimensi kolom

\begin{tabular}{|c|c|c|c|c|c|c|c|c|}
\hline \multirow{2}{*}{\multicolumn{3}{|c|}{$\begin{array}{c}\text { Kolom } \\
\text { (Tingkat } \\
\text { Lantai) }\end{array}$}} & \multirow{2}{*}{$\begin{array}{l}\mathrm{L} \\
(\mathrm{m})\end{array}$} & \multirow{2}{*}{$\begin{array}{c}\mathrm{f}^{\prime} \mathrm{c} \\
(\mathrm{Mpa})\end{array}$} & \multicolumn{2}{|c|}{ Interior } & \multicolumn{2}{|c|}{ Exterior } \\
\hline & & & & & $\mathrm{b}(\mathrm{mm})$ & $\mathrm{h}(\mathrm{mm})$ & $\mathrm{b}(\mathrm{mm})$ & $\mathrm{h}(\mathrm{mm})$ \\
\hline & 1 & & 4 & 50 & 800 & 1300 & 700 & 1200 \\
\hline 2 & - & 8 & 3,5 & 50 & 700 & 1150 & 700 & 1200 \\
\hline 9 & - & 15 & 3,5 & 50 & 600 & 1000 & 700 & 1100 \\
\hline 16 & - & 22 & 3,5 & 50 & 500 & 900 & 700 & 1000 \\
\hline 23 & - & 29 & 3,5 & 40 & 500 & 800 & 650 & 900 \\
\hline 30 & - & 36 & 3,5 & 40 & 500 & 700 & 600 & 800 \\
\hline 37 & - & 43 & 3,5 & 40 & 500 & 600 & 550 & 700 \\
\hline 44 & - & 50 & 3,5 & 40 & 500 & 500 & 500 & 600 \\
\hline
\end{tabular}

D. Shearwall

Digunakan shearwall dengan tebal $300 \mathrm{~mm}$ dan mutu beton $\mathrm{f}^{\prime} \mathrm{c}=50 \mathrm{Mpa}$. 
4. Balok tinggi

Digunakan balok tinggi dengan dimensi 400 x $2000 \mathrm{~mm}$ dan mutu beton f'c $=35 \mathrm{Mpa}$.

\section{Struktur Sekunder}

Struktur sekunder adalah elemen struktur yang direncanakan hanya memikul beban ultimit akibat gravitasi saja, tanpa meninjau beban gempa. Hasil perencanaan struktur sekunder seperti yang disajikan poin A dan poin B.

\section{Pelat}

Rekapitulasi hasil penulangan pelat ditunjukan pada Tabel 3 dan Tabel 4.

Tabel 3.

Rekapitulasi penulangan pelat lantai dan atap

\begin{tabular}{|c|c|c|c|c|}
\hline & Tumpuan $\mathrm{X}$ & Lapangan X & Tumpuan Y & Lapngan Y \\
\hline Tebal pelat (mm) & 120 & 120 & 120 & 120 \\
\hline Tulangan utama & D10 - 240 & D10 - 240 & D10 -240 & $\mathrm{D} 10-240$ \\
\hline Tulangan bagi & $\varnothing 8-300$ & - & $\varnothing 8-300$ & - \\
\hline \multicolumn{5}{|c|}{$\begin{array}{c}\text { Tabel } 4 . \\
\text { Rekapitulasi penulangan pelat tangga dan bordes }\end{array}$} \\
\hline Tebal pelat $(\mathrm{mm})$ & \multicolumn{4}{|c|}{150} \\
\hline Tulangan utama & \multirow{2}{*}{\multicolumn{4}{|c|}{$\begin{array}{l}\text { D13-200 } \\
\varnothing 8-300\end{array}$}} \\
\hline Tulangan bagi & & & & \\
\hline
\end{tabular}

\section{Balok}

Rekapitulasi hasil penulangan balok yang meliputi balok anak, balok lift, dan balok tangga ditunjukan pada Tabel 5 .

Tabel 5.

Rekapitulasi penulangan balok

\begin{tabular}{|c|c|c|c|c|c|c|c|}
\hline \multicolumn{8}{|c|}{ Rekapitulasi penulangan balok } \\
\hline \multirow{3}{*}{$\begin{array}{c}\text { Balo } \\
\text { k }\end{array}$} & \multicolumn{2}{|c|}{ Dimensi } & \multicolumn{4}{|c|}{ Lentur } & \multirow{3}{*}{ Geser } \\
\hline & \multirow{2}{*}{$\begin{array}{c}\mathrm{b} \\
\mathrm{m} \\
\mathrm{m})\end{array}$} & \multirow{2}{*}{$\begin{array}{c}\mathrm{h} \\
(\mathrm{m} \\
\mathrm{m})\end{array}$} & \multicolumn{2}{|c|}{ Tumpuan } & \multicolumn{2}{|c|}{ Lapangan } & \\
\hline & & & $(+)$ & $(-)$ & $(+)$ & $(-)$ & \\
\hline Anak & 200 & 350 & $\begin{array}{c}5 \\
\text { D16 }\end{array}$ & $\begin{array}{c}2 \\
\text { D16 }\end{array}$ & $\begin{array}{c}2 \\
\text { D16 }\end{array}$ & $\begin{array}{c}3 \\
\text { D1 }\end{array}$ & $\begin{array}{c}\text { D10- } \\
140\end{array}$ \\
\hline Lift & 300 & 400 & $\begin{array}{c}6 \\
\text { D19 }\end{array}$ & $\begin{array}{c}2 \\
\text { D19 }\end{array}$ & $\begin{array}{c}2 \\
\text { D19 }\end{array}$ & $\begin{array}{c}6 \\
3 \\
\text { D1 } \\
9\end{array}$ & $\begin{array}{c}\text { D10- } \\
170\end{array}$ \\
\hline $\begin{array}{c}\text { Tang } \\
\text { ga }\end{array}$ & 300 & 350 & $\begin{array}{c}2 \\
\text { D16 }\end{array}$ & $\begin{array}{c}2 \\
\text { D16 }\end{array}$ & $\begin{array}{c}2 \\
\text { D16 }\end{array}$ & $\begin{array}{c}2 \\
\text { D1 } \\
6\end{array}$ & $\begin{array}{c}\text { D10- } \\
140\end{array}$ \\
\hline
\end{tabular}

\section{B. Analisa Struktur}

Hasil analisa struktur perlu dikontrol sesuai syarat pada SNI [6]. Hal tersebut dilakukan untuk meninjau kelayakan struktur dalam memikul beban yang bekerja. Berikut ini adalah kontrol - kontrol yang dilakukan terhadap hasil analisa struktur:

- Berat sendiri bangunan

$\mathrm{W}_{\text {manual }}=64064513,34 \mathrm{Kg}$

$\mathrm{W}_{\text {ETABS }}=65718472,12 \mathrm{Kg}$

Sehingga didapat selisih $\mathrm{W}_{\text {manual }}$ dan $\mathrm{W}_{\text {ETABS }}$ sebesar $2,52 \%$

- Jumlah respons ragam

Pada mode ke-17 syarat partisipasi sebesar $\geq 90 \%$ telah terpenuhi. Dengan arah-X 92\% dan arah-Y 95\%

- Perioda struktur dan skala gaya gempa

Untuk prosedur desain didapat:

$\mathrm{T}_{\mathrm{cx}}=4,637$ detik dan $\mathrm{T}_{\mathrm{cy}}=11,905$ detik dengan skala gaya gempa $\mathrm{V}_{\mathrm{dx}}=1,54$ dan $\mathrm{V}_{\mathrm{dy}}=2,75$

Untuk prosedur kontrol simpangan didapat:

$\mathrm{T}_{\mathrm{cx}}=8,128$ detik dan $\mathrm{T}_{\mathrm{cy}}=11,905$ tanpa skala gaya.

- Simpangan antar lantai

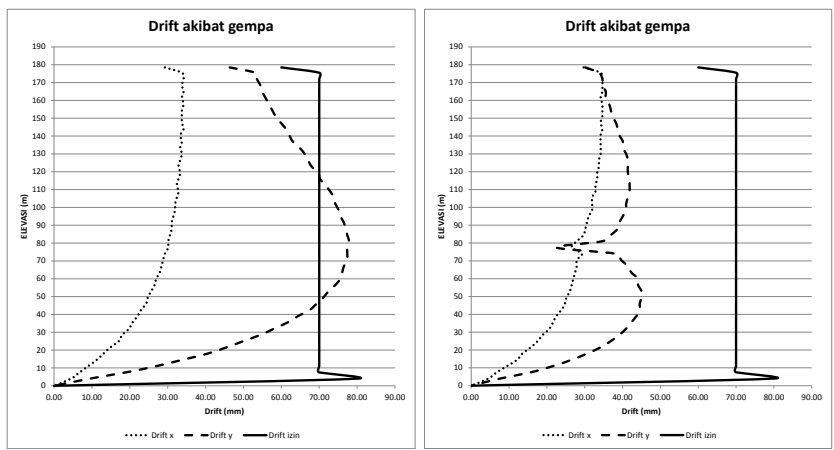

(a)

(b)

Gambar 5. Simpangan antar lantai akibat gempa

Seperti yang dapat dilihat pada Gambar 5 (a) adalah grafik simpangan antar lantai sebelum menggunakan sistem outrigger. Dimana simpangan arah Y melebihi batas simpangan ijin. Gambar 5 (b) adalah grafik simpangan antar lantai setelah menggunakn sistem outrigger. Simpangan arah $\mathrm{Y}$ yang sebelumnya melebihi ijin, setelah menggunkan sistem outrigger simpangan menjadi memenuhi ijin, baik arah $\mathrm{X}$ maupun arah Y.

\section{Struktur Primer dan Outrigger}

Struktur primer/struktur utama berfungsi untuk menahan beban gravitasi dan beban lateral. Sedangkan outrigger berfungsi menambah kekakuan bangunan. Hasil perencanaan yang ditunjukan pada poin $\mathrm{A}$ - poin $\mathrm{D}$ dan harus dipastikan memenuhi syarat yang tercantum pada SNI [6].

\section{Balok induk}

Didapat contoh sket penulangan balok induk seperti pada Gambar 6.

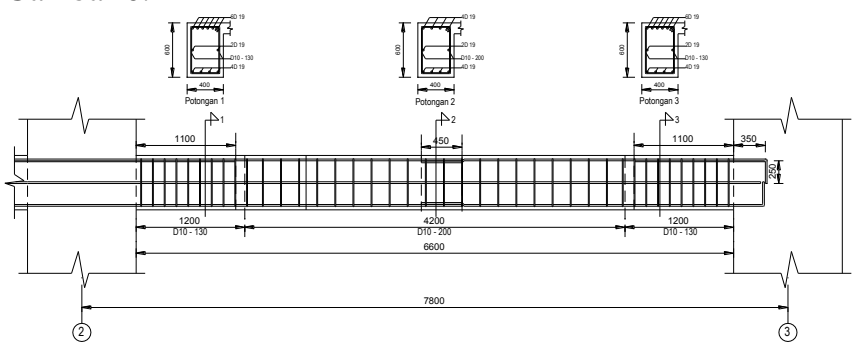

Gambar 6. Sket penulangan balok induk As. 2-A;3-A Lt.2

Tulangan dipasang 1 lapis, sebanyak 4 buah, maka cek jarak tulangan:

$$
\begin{aligned}
& S=\frac{b_{w}-2 s-N \cdot D-2 . D}{N-1} \geq 25 \mathrm{~mm} \\
& S=\frac{400-2.40-4.19-2.10}{4-1} \geq 25 \mathrm{~mm} \\
& S=74,67 \mathrm{~mm} \geq 25 \mathrm{~mm}(\text { Okay })
\end{aligned}
$$

Panjang penyaluran tulangan berkait: $1_{\mathrm{dh}}=\frac{0,24 \times f_{y} \times d b}{\sqrt{f_{c}}}=\frac{0,24 \times 420 \times 19}{\sqrt{30}}=349,66 \mathrm{~mm} \approx 350 \mathrm{~mm}$

\section{Kolom}

Didapat contoh sket penulangan kolom seperti pada Gambar 7.

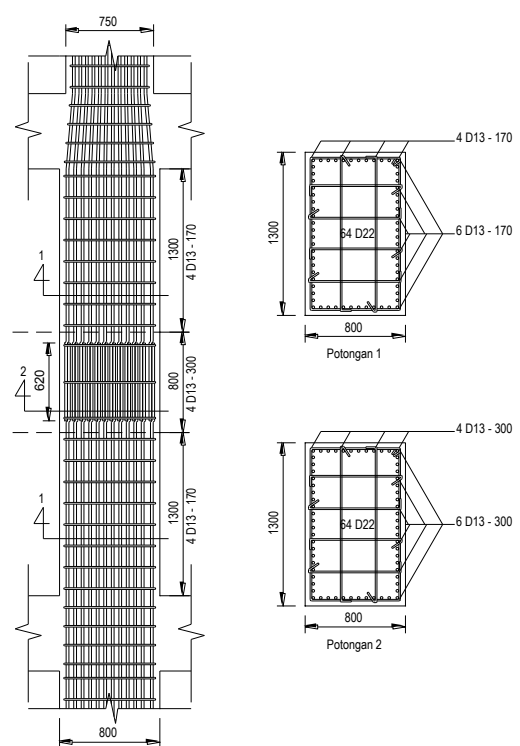

Gambar 7. Sket hasil perhitungan tulangan kolom As. 2-B

- Cek batas tulangan komponen tekan:

$1 \%<2,38 \%<8 \%$ (Okay)

- Cek batas spasi bersih tulangan: 33,94 mm > $25 \mathrm{~mm}$ (Okay)

Panjang sambungan lewatan:

$1_{\mathrm{d}}=\left(\frac{420}{1,1.1 . \sqrt{50}} \times \frac{1.1 .1}{2,5}\right) \times 22=475,18 \mathrm{~mm}$ 
Karena seluruh tulangan pada panjang lewatan disambung, maka sambungan lewatana termasuk kelas B. Sehingga panjang penyaluran untuk kelas $\mathrm{B}$ adalah:

$1,3 l_{d}=1,3 \times 475,18=617,73 \mathrm{~mm} \approx 620 \mathrm{~mm}$

\section{HBK (Hubungan Balok - Kolom)}

Didapat contoh sket penulangan hubungan balok - kolom seperti pada Gambar 8. Dimana Gambar 8 (a) menunjukan tampak atas dari HBK, sedangkan Gambar 8(b) menunjukan dari potongan $1 \mathrm{HBK}$.

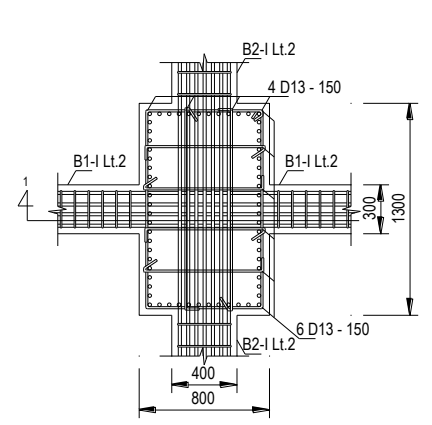

(a)

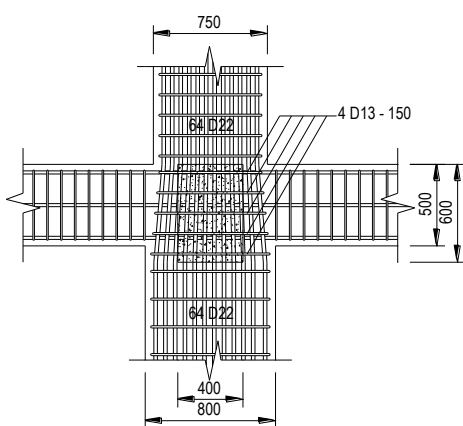

(b)
Gambar 8. Sket penulangan HBK

Kebutuhan tulangan geser:

$0,5 \times \frac{A_{s h}}{\mathrm{~S}}=0,5 \times \frac{441,875}{175}=1,263 \mathrm{~mm}^{2} / \mathrm{mm}$

Dipakai 4 D13, $\mathrm{A}_{\mathrm{sh}}=441,875 \mathrm{~mm}^{2}$

$s=\frac{441,875}{1,263}=350 \mathrm{~mm}^{2}$

Syarat:

$\mathrm{s}<150 \mathrm{~mm}$

$350 \mathrm{~mm}>150 \mathrm{~mm}($ Not Okay)

$\rightarrow$ Maka digunakan 4 D13 - 150

Cek:

$\varphi . \mathrm{V}_{\mathrm{n}}>\mathrm{V}_{\mathrm{u}}$

$0,75 \times 12501,6>1209,48 \mathrm{kN}$

$9376,24 \mathrm{kN} \quad>1209,48 \mathrm{kN}$ (Okay)

4. Shearwall

Pada sistem outrigger digunakan corewall sebagai pusat dari struktur, dimana corewall didesain menggunakan elemen shearwall. Didapat contoh sket penulangan shearwall seperti pada Gambar 9.

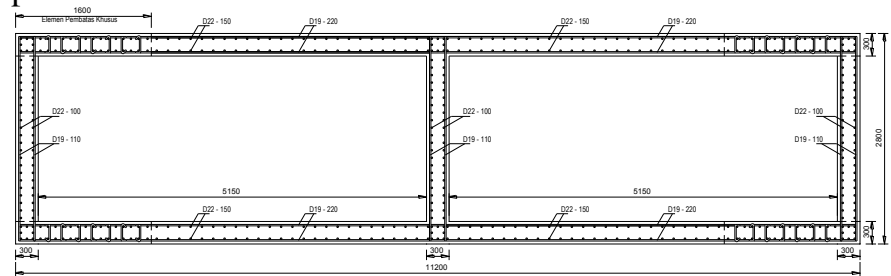

Gambar 9. Sket hasil perhitungan tulangan shearwall

Cek batas minimum tulangan tranversal::

- Dinding arah X

$$
\mathrm{P}_{\mathrm{t}}=\frac{A_{v}}{t \times s}=\frac{567,06}{300 \times 220}=0,0086>0,0025 \text { (Okay) }
$$

- Dinding arah X

$$
\mathrm{P}_{\mathrm{t}}=\frac{A_{v}}{t \times s}=\frac{567,06}{300 \times 110}=0,0172>0,0025 \text { (Okay) }
$$

Rasio tulangan longitudinal harus memenuhi:

$0,0149>0,0025$ (Okay)

\section{Couple beam}

Dinding struktur yang memiliki bukaan harus dihubungkan menggunakan couple beam. Dimana ketika terjadi gempa sendi plastis direncanakan terlebih dahulu pada balok kopel sebelum dasar dinding mengalami sendi plastis. Didapat contoh sket penulangan couple beam seperti pada Gambar 10.

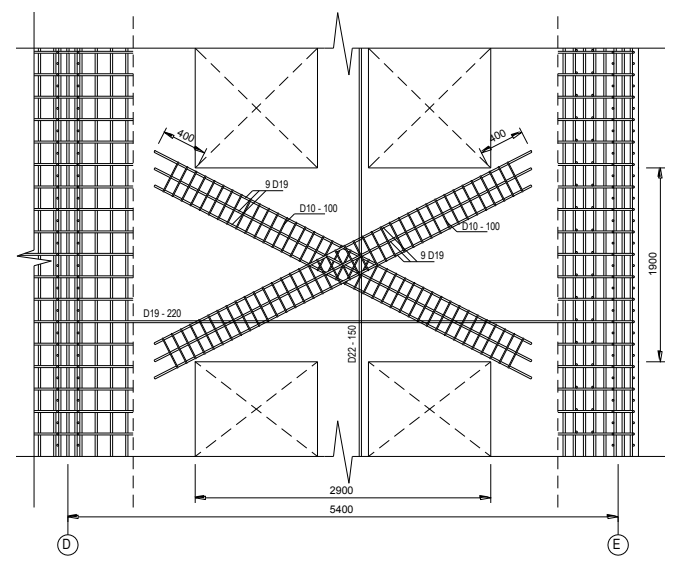

Gambar 10. Sket penulangan balok kopel As. D-E

persayaratan geometris balok kopel sebagai berikut:

- $\frac{l_{n}}{h} \geq 4 \rightarrow \frac{2900}{1900} \geq 4 \rightarrow 1.53<4$ (Not Okay)

- $\frac{l_{n}}{h} \leq 2 \rightarrow \frac{2900}{1900} \leq 2 \rightarrow 1.53<2$ (Okay)

$V_{u} \geq 0,33 \cdot \lambda \cdot \sqrt{f_{c}} \cdot A_{c w}$

$2825901 \geq 0,33 \cdot 1 \cdot \sqrt{50} \cdot(300 \times 1900)$

$2825901 N>1330067,86 N$ (Okay)

Dari kedua syarat geometris tersebut maka diketahui balok kopel harus didesain dengan dua kelompok tulangan yang berpotongan ditempatkan secaradiagonal simetris terhadap tengah bentang.

6. Outrigger dan Belt-truss

Didapat contoh sket penulangan balok tinggi seperti pada Gambar 11.

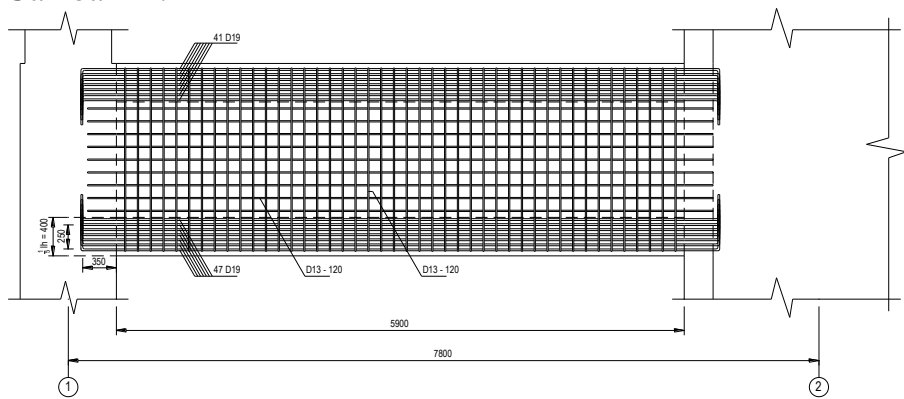

Gambar 11. Sket penulangan balok tinggi As. 1-C;2-C

Dari hasil perhitungan didapat tulangan atas 41 D19 yang didistribusikan merata setinggi $1 / 5 \mathrm{~h}$ pada daerah tarik balok: $0,2 \times \mathrm{h}=0,2 \times 2000=400 \mathrm{~mm}$

Kontrol jarak tulangan:

Tulangan dipasang 7 lapis, lapis 1-6 sebanyak 6 buah tulangan dan lapis ke-7 sebanyak 5 buah tulangan, maka:

Jarak antar tulangan tiap baris:

$$
\begin{aligned}
& S=\frac{b_{w}-2 s-N . D-2 . D}{N-1} \geq 25 \mathrm{~mm} \\
& S=\frac{400-2.40-6.19-2.13}{6-1} \geq 25 \mathrm{~mm} \\
& S=36 \mathrm{~mm} \geq 25 \mathrm{~mm} \text { (Okay) } \\
& \text { Jarak antar tulangan tiap lapis: } \\
& S=\frac{b_{w}-s-N . D-2 . D}{N-1} \geq 25 \mathrm{~mm} \\
& S=\frac{400-40-6.19-2.13}{7-1} \geq 25 \mathrm{~mm} \\
& S=33,5 \mathrm{~mm} \geq 25 \mathrm{~mm}(\text { Okay) }
\end{aligned}
$$

7. HBK outrigger - kolom eksterior

Didapat contoh sket penulangan HBK outrigger - kolom eksterior seperti pada Gambar 12.

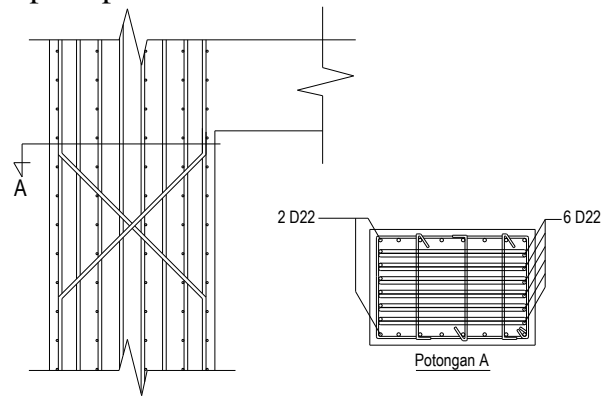

Gambar 12. Sket penulangan HBK outrigger - kolom 
Kolom yang terhubung dengan balok outrigger akan menerima momen yang sangat besar. Untuk mengatasi masalah tersebut maka dibuat tulangan silang pada kolom. Sehingga kolom berperilaku seperti sendi dan momen yang diterima kolom tidak terlalu besar. Seperti yang dapat dilihat pada Gambar 12 dimana 6 tulangan tiap sisinya ditekuk bersebrangan dan 2 tuangan dibiarkan menerus.

\section{Daktilitas Kolom Outrigger}

Untuk mengetahui nilai daktilitas kolom outrigger menggunakan program bantu Xtract dengan dengan nilai nilai yang diinput mengikuti pendekatan yang dijelaskan oleh Razvi dan Saatcioglu [14]. Atau bisa juga menggunakan pendeketan lain dengan penjelasan yang lebih jauh sesuai dengan literatur terkait [15][16][17]. Sehingga didapat output berupa garfik cuvature - momen seperti pada Gambar 13 .

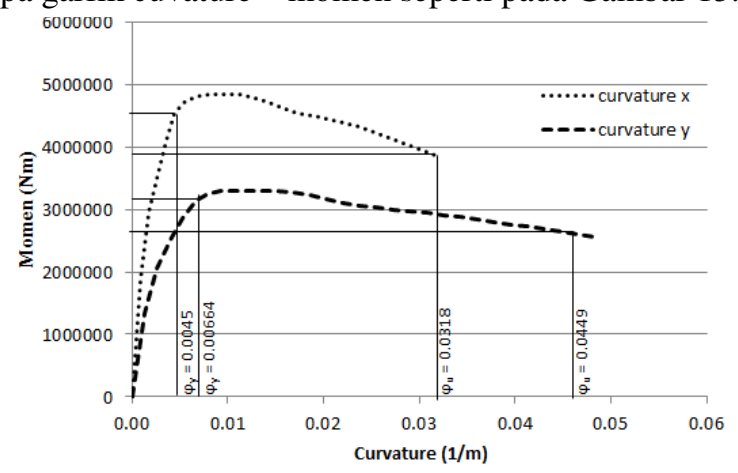

Gambar 7. 10 Grafik hubungan momen - curvature kolom

Sehingga didapat nilai daktilitas:

- Arah-X

Kondisi leleh (yield):

$\varphi_{\mathrm{y}}=0,00451 / \mathrm{m}$

$\mathrm{M}_{\mathrm{x}}=4536000 \mathrm{Nm}$

Kondisi 0,8 dari puncak (ultimit):

$\varphi_{\mathrm{u}}=0,03181 / \mathrm{m}$

$\mathrm{M}_{\mathrm{x}}=3881600 \mathrm{Nm}$

Daktilitas:

$\frac{0,0318}{0,0045}=7,11$

- Arah-Y

Kondisi leleh (yield):

$\varphi_{\mathrm{y}}=0,006641 / \mathrm{m}$

$\mathrm{M}_{\mathrm{y}}=3140000 \mathrm{Nm}$

Kondisi 0,8 dari puncak (ultimit):

$\varphi_{\mathrm{u}}=0,04491 / \mathrm{m}$

$\mathrm{M}_{\mathrm{y}}=2644800 \mathrm{Nm}$

Daktilitas:

$\frac{0,0449}{0,00664}=6,76$

Sehingga nilai yang menentukan adalah daktilitas arah $\mathrm{Y}$ sebesar 6,76. Sehingga nilai $\mathrm{R}=5$ yang digunakan untuk mendesain beban gempa dianggap masih memenuhi.

\section{KESIMPULAN}

Kesimpulan yang dapat daimbil khususnya terkait Sistem Outrigger dan Belt-Truss yaitu sebagai berikut:
1. Simpangan antar lantai untuk arah-Y melebihi batas ijin yang ditentukan sesuai dengan SNI. Maka dipasang Balok Outrigger dengan dimensi $400 \mathrm{~mm}$ x $2000 \mathrm{~mm}$ dan BeltTruss dengan dimensi yang sama pada lantai tingkat 22 . Setelah dilakukan analisa ulang dengan Sistem Outrigger dan Belt-Truss, simpangan antar lantai dapat memenuhi syarat SNI.

2. Nilai daktilitas Kolom Outrigger adalah sebesar 6,76 yang mana lebih besar dari koefisien reduksi gempa (R) yang direncanakan sebesar 5. Sehingga daktilitas bangunan (khususnya Kolom Outrigger) dengan koefisien $\mathrm{R}=5$ dapat terpenuhi.

3. Untuk hasil perencanaan lebih detail di lampirkan dalam bentuk gambar perencanaan.

\section{SARAN}

Saran yang bisa diberikan berdasar hasil analisa adalah diperlukan studi lebih lanjut berkaitan dengan daktilitas struktur yang menggunakan sistem outrigger dan belt-trus.

\section{DAFTAR PUSTAKA}

[1] P. R. Nanduri, B. Suresh, and M. I. Hussain, "Optimum Position of Outrigger System for High-Rise Reinforced Concrete Buildings Under Wind And Earthquake Loadings," Am. J. Eng. Res., pp. 7689, 2013

[2] M. Ali and K. S. Moon, "Structural Developments in Tall Buildings: Current Trends and Future Prospects," Archit. Sci. Rev., pp. 205 223, 2007.

[3] H. Choi, G. Ho, L. Joseph, and N. Mathias, "Outrigger Design for High-Rise Building: An output of the CTBUH Outrigger Working Group," Chicago, 2012.

[4] M. Gazali and D. Iranata, "Studi Perbandingan Perilaku Bangunan Menggunakan SRPM, SRBK, dan SRBK Menggunakan Outrigger Terhadap Variasi Tinggi Gedung," J. POMITS, vol. 1, no. 2, 2012.

[5] Y. Syahriar, M. Mukarrom, D. Iranata, and T. W. Adi, "Analisis Perbandingan Efektifitas Struktur Gedung dengan Menggunakan Shearwall dan Kombinasi Antara Shearwall-Outrigger," J. POMITS, vol. 1, no. 1, 2012.

[6] Badan Standarisasi Nasional, "Tata Cara Perencanaan Ketahanan Gempa untuk Struktur Bangunan Gedung dan Non Gedung ( SNI 1726:2012 )," Jakarta, 2012.

[7] Badan Standardisasi Nasional, "SNI 2847-2013: Persyaratan beton struktural untuk bangunan gedung," Jakarta, 2013

[8] Badan Standarisasi Nasional, "SNI 1727:2013 Beban Minimum Untuk Perancangan Bangunan Gedung dan Struktur Lain,” Jakarta, 2013.

[9] American Society of Civil Engineers, "Minimum Design Loads for Buildings and Other Structures," Reston, Virigina, 2010.

[10] Direktorat Penyelidikan Masalah Bangunan, "Peraturan Pembebanan Indonesia Untuk Gedung,” Bandung, 1983.

[11] Derpartemen Pekerjaan Umum, "Peraturan Beton Bertulang Indonesia," Bandung, 1971.

[12] B. S. Taranath, Structural Analysis and Design for Tall Buildings. Boca Raton: CRC Press, 2012.

[13] P. S. Kian and F. T. Siahaan, "The Use of Outrigger and Belt-Truss System for High-Rise Concrete Buildings," Dimens. Tek. Sipil, pp 36-41, 2001

[14] S. Razvi and M. Saatcioglu, "Confinement Model for High-Strength Concrete," J. Struct. Eng., pp. 281-289, 1999.

[15] R. Park and T. Paulay, Reinforced Concrete Structures. Christchurch: Wiley-Interscience, 1974.

[16] T. Paulay and M. Priestley, Seismic Design of Seismic of Reinforced Concrete and Masonry Buildings. Canada: John Wiley \& Sons, 1992.

[17] M. Priestley, G. Calvi, and M. Kowalsky, Displacement-Based Seismic Design of Structures. Pavia: IUSS Press, 2007. 